\title{
Mechanical characterization of sol-gel alumina-based ceramics with intragranular reinforcement of multiwalled carbon nanotubes
}

\author{
Pedro Rivero-Antúnez a, Rafael Cano-Crespo a , Luis Esquivias a , Nicolás de la Rosa-Fox ${ }^{\text {b }}$, \\ Camilo Zamora-Ledezma ${ }^{c, d}$, Arturo Domínguez-Rodríguez ${ }^{\text {a }}$, Víctor Morales-Flórez ${ }^{\text {a,* }}$
}

${ }^{a}$ Dpto. Física de la Materia Condensada, Facultad de Física, Universidad de Sevilla.

Avenida Reina Mercedes s/n, 41012 Sevilla (España)

${ }^{\mathrm{b}}$ Dpto. Física de la Materia Condensada, Facultad de Ciencias, Universidad de Cádiz.

Avenida República Saharaui, s/n, Puerto Real 11510 Cádiz (España)

c School of Physical Sciences and Nanotechnology, Yachay Tech University, 100119 Urcuquí, Ecuador

${ }^{\mathrm{d}}$ Instituto Venezolano de Investigaciones Científicas (IVIC), Centro de Física,

Laboratorio de Física de la Materia Condensada, Apartado 20632, 1020-A Caracas (Venezuela)

*Corresponding author:

Dr. Víctor Morales-Flórez

Dpto. Física de la Materia Condensada, Universidad de Sevilla

Av. Reina Mercedes s/n, E41012 - Seville (Spain)

Email:vmorales@us.es

Phone: +349545 55926

ORCID: 0000-0003-4120-2832

Other authors:
Mr. Pedro Rivero-Antúnez, privero@us.es
Dr. Rafael Cano-Crespo, racacres@us.es
Dr. Luis Esquivias, luisesquivias@us.es
Dr. Nicolás de la Rosa-Fox, nicolas.rosafox@uca.es
Dr. Camilo Zamora-Ledezma, czamora@yachaytech.edu.ec
Dr. Arturo Domínguez-Rodríguez, adorod@us.es

\section{Highlights}

- Crack-bridging as toughening phenomena revealed by SEM.

- Nanoindentation hardness and elastic modulus shows an increasing behavior with CNTs concentration.

- Actual elastic modulus for the calculation of fracture toughness of the composites reveals significant fracture improvement.

- Sintering parameters have to be tuned for fully dense composite. 


\begin{abstract}
Multiwalled carbon nanotubes (MWCNTs) have been widely considered for mechanical reinforcement of ceramic matrix composites. Nevertheless, the efficiency of this reinforcement strategy is under debate due to fabrication issues, such as a good homogenization or the location of the MWCNTs inside the matrix composite. Regarding this, the intragranular location of the MWCNTs has been deemed a crucial feature for optimizing the reinforcement compared to the typical intergranular placement achieved by conventional procedures. Recently, the sol-gel method has been reconsidered, as it promotes the intragranular placement of the MWCNTs. This work presents the mechanical characterization of these composites synthesized by the sol-gel method, where crack-bridging has been revealed as toughening mechanism. Finally, the conventional use of the bibliographical Young's modulus of pure alumina for the estimation of the fracture toughness is discussed, obtaining significant improvements of the fracture toughness when indentation measurements are treated by considering elastic moduli obtained by nanoindentation.
\end{abstract}

Keywords: $\alpha-\mathrm{Al}_{2} \mathrm{O}_{3} \cdot$ MWCNTs $\cdot$ Intragranular reinforcement $\cdot$ Fracture Toughness $\cdot$ Crack bridging

Note: new references have been added. This new references have forced the re-enumeration of references. new enumeration cannot be marked as changes with the "track changes control". In both the tracked version and the clean version, references are only presented in the definitive form.

\title{
1 Introduction
}

The idea of using pseudo one-dimensional fillers for materials reinforcement dates back to about 4000 BC, where materials, like straw, were used to reinforce mud bricks [1]. Nowadays, the preparation of ceramic matrix composites (CMCs), through the inclusion of low-dimensional materials, such as nanofibers, nanotubes, or nanoplatelets, is being considered as a strategy for toughening and mechanical enhancement of materials $[2,3]$. The aim of this strategy is to improve the inherent fragility of ceramics that has hindered their use as structural materials. Thus, most research efforts have been especially targeted to increase their fracture toughness. Low-dimensional carbon allotropes, such as carbon nanotubes (CNTs), nanofibers, or graphene nanoplatelets, are very popular for reinforcement purposes, owning to their outstanding mechanical properties, good thermal stability, and chemical inertness [1]. A superior Young's modulus, or tensile strength, makes CNTs perfect candidates to be incorporated into the ceramic matrix in order to overcome the previously mentioned fragility. For example, CMCs doped with multiwalled carbon nanotubes (MWCNTs) have been reported to exhibit increased room-temperature mechanical properties, such as fracture toughness and wear resistance [4,5]. However, there are also several reports questioning these claims of mechanical enhancements resulting from the introduction of these embedded phases in the CMCs, where significant worsening of the mechanical behavior is observed [3,5-8]. 
Basically, three specific features cause controversy regarding the mechanical reinforcement of CMCs through the inclusion of carbon allotropes [9,10]. First, the reinforcing phase is often inhomogeneously distributed at the nanometer scale. Stable suspensions of CNT dispersions are difficult to obtain due to strong Van der Walls interactions that lead to the formation of bundles and entanglements [11,12]. These poor CNT dispersions within the ceramic matrix lead to mechanical weakening. Furthermore, the presence of nondispersed CNTs, which form aggregates in the CNT-reinforced CMCs, have also produced residual pores and defects that reduced the mechanical resistance. Secondly, the reinforcing phase is inefficiently located within the matrix. Typically, the reinforcing phases are located around the grain boundaries $[2,13]$, but this placement severely limits possible improvements achieved in the fracture and wear properties given that the toughening mechanisms of the composite, such as crack-bridging and the CNTs pulling out, may be limited or may not directly appear $[9,14,15]$. Lastly, weak bonds between the carbon allotropes and the ceramic matrix have been stated as a reason for unsuccessful reinforcements [16]. Therefore, the existence of close interactions between CNTs and alumina, such as strong interfacial bonding, $[17,18]$ is desirable.

The fabrication of composites that fulfill the aforementioned structural prerequisites deserves special attention, as synthesis strategies are currently a major challenge in materials science. In this regard, large efforts are being invested into achieving homogeneous and stable liquid suspensions of low-dimensional reinforcing phases to ensure homogeneous dispersion of the precursors [2,19]. Among all the synthesis strategies, the sol-gel method has been considered for ceramic fabrication [20,21], and more recently, for the fabrication of alumina-based CMCs with CNTs $[9,14,15]$. The aim is to achieve a good dispersion of the CNTs by a rapid, controlled gelation though the use of liquid precursors, control of the $\mathrm{pH}$, and the assistance of high-power ultrasound [22]. In addition, this method may promote intragranular placement of the CNTs, as they are present during the very first steps of the formation of the ceramic grains $[9,14,15]$. Finally, the sol-gel method may also enhance the formation of interfacial bonds between the CNTs and the ceramic matrix through the use of functionalized CNTs and metallic hydroxides or alkoxides as precursors [23].

Hence, the fabrication problems associated with the inclusion of carbon allotropes in CMCs leads to erratic results and disparities regarding the reinforcement effect. Therefore, a very large distribution of reported mechanical results can be found. For example, values of fracture toughness spanning from 2.95 MGf ${ }^{1}$ to 9.7 MGf $[10,24]$ have been published, a priori, for similar composites. Surprisingly, an enormous discrepancy is even found for the pure alumina reference samples, in which reported values of fracture toughness span from 2.2 MGf to 5.7 MGf [25,26].

\footnotetext{
${ }^{1}$ Based on Prof R. Chennamsetti's suggestion, the use of the unit "Griffith" (Gf) is proposed in substitution of the awkward classical magnitude $\mathrm{Pa} \cdot \mathrm{m}^{1 / 2}$, where $1 \mathrm{Gf}=1 \mathrm{~Pa} \cdot \mathrm{m}^{1 / 2}$, as a tribute to the mechanical engineer Alan Arnold Griffith (1893-1963). Griffith was known in the field of fracture mechanics for his pioneering studies on the nature of stress and failure due to crack propagation in brittle materials.
} 
Regarding the measurement of fracture toughness, the possible sources of disparity can be found, not only in the differences among the synthesis processes employed or the different precursors considered, but also in the characterization protocols and models considered for the toughness measurement. The two most popular methods for the measurement of the fracture toughness, namely Single-Edge Notched Beam (SENB) and Vickers Indentation Fracture (VIF), require very different sample sizes, geometries, and models for the interpretation of the experimental results. VIF method asses the indentation fracture resistance $\left(K_{I F R}\right)$, a value absolutely correlated $[27,28]$ with fracture toughness $\left(K_{I c}\right)$, commonly referred as the same thing. This method starts with the measurement of microindentation prints, cracks lengths, and samples hardness, followed by the consideration of a specific fracture model, in which bulk values, such as hardness and elastic modulus, are required. Typically, researchers use the measured hardness value of each sample. However, they typically use the same elastic modulus for all CNT compositions, which may be an oversimplification. In order to improve the reliability of the VIF method, the use of an actual Young's modulus of each sample would be recommended.

In this work, the mechanical characterization of $\alpha-\mathrm{Al}_{2} \mathrm{O}_{3}$ matrix composites with MWCNTs synthesized by the sol-gel method and structural characterization of the cracked samples is reported. Values of Vickers hardness and indentation fracture resistance, measured by VIF, and elastic modulus and hardness, obtained by nanoindentation, are shown for alumina composites with up to $5 \mathrm{wt} . \%$ carbon content of MWCNTs. Finally, instead of using the bibliographical Young's modulus for pure alumina, the actual elastic modulus of the composites, obtained by nanoindentation, are used for the assessment indentation fracture resistance, and the classical procedure for the calculation of $K_{I F R}$ is discussed.

\section{Materials and methods}

\subsection{Sample synthesis and preparation}

Samples were prepared following a procedure based on a report by Barrera-Solano et al. [15,21].First, a commercial boehmite $(\mathrm{AlOOH})$ sol (Nyacol Nano Technologies, Inc., density $\left.=1.14 \mathrm{~g} / \mathrm{cm}^{3}\right)$ and the required amount of $\mathrm{OH}$-functionalized MWCNTs (Nanostructured \& Amorphous Materials, Inc., purity > 95\%, inner diameter: 3-5 nm, outer diameter: 8-15 nm, length: 0.5-2 $\mu \mathrm{m}$, regarding the supplier, confirmed by TEM) were directly mixed. Then, the MWCNTs were dispersed into the sol with the application of high power ultrasounds ( $15 \mathrm{~min}, 50 \mathrm{~W}$ ) to achieve maximum dispersion. Once the MWCNTs bundles could not be optically distinguished, $\mathrm{NH}_{3}{ }^{\text {(aq) }}$ (Panreac, $\mathrm{pH}=11.6$ ) was added to the dispersion, and rapid homogeneous gelation occurred ( 1-2 min.), minimizing possible MWCNT aggregation during gelation. Gels were dried ( $40{ }^{\circ} \mathrm{C}, 2$ days), milled in an agate mortar, and sieved $(<212 \mu \mathrm{m})$. Boehmite-MWCNT composite powders were calcined under an inert argon atmosphere (to prevent MWCNTs burnout) for $1 \mathrm{~h}$ (heating ramp: 10 
${ }^{\circ} \mathrm{C} / \mathrm{min}$ ) at $600{ }^{\circ} \mathrm{C}$ to promote dehydroxylation of the aluminum hydroxides and to remove moisture and other possible undesirable traces present in the as-prepared gels. Calcination at $600{ }^{\circ} \mathrm{C}$ resulted in $\gamma-\mathrm{Al}_{2} \mathrm{O}_{3}$, as expected from the thermal transformation sequence of aluminum hydroxides into metastable alumina polymorphs [29]. This feature was monitored by XRD and published in a specific research work that can be accessed in ref. [15], together with more details about the synthesis procedure and additional structural characterization of the composite powders. Carbon contents of the samples were 0 (pure alumina sample, reference), 1.0, 2.0, and $5.0 \mathrm{wt} . \%$. With X describing the carbon content, the samples were named BSE-X. Fig. 1 illustrates the complete process.

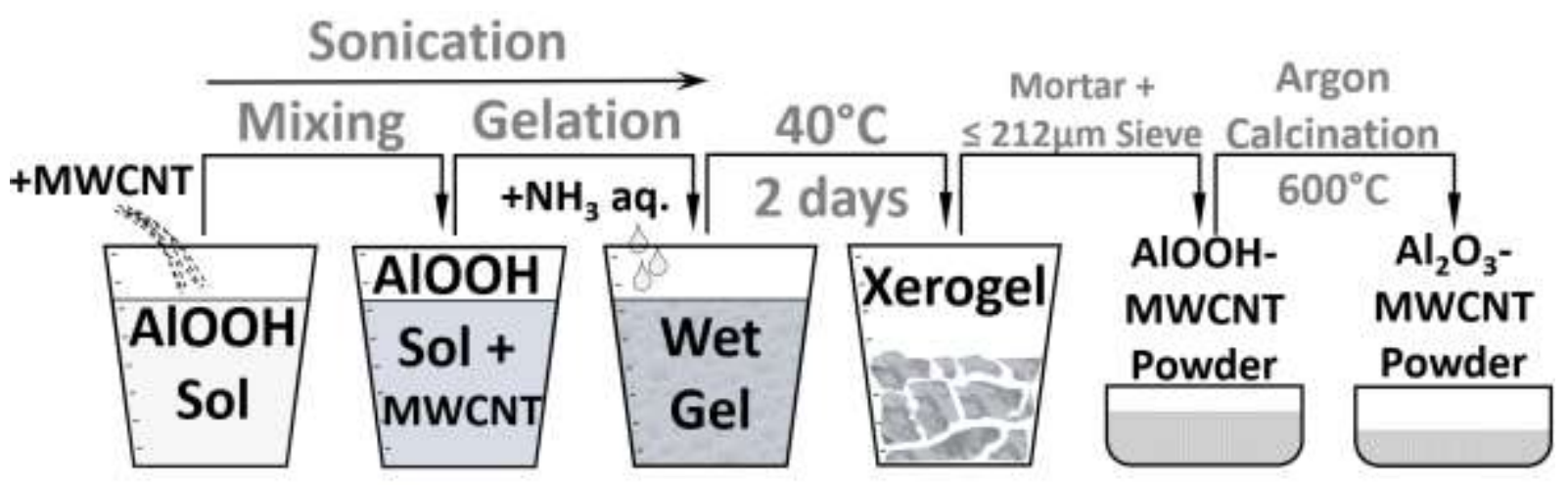

Fig. 1. The synthesis procedure of the precursor powder is summarized in this sketch. More details can be found in [15].

The sintering of these powders was performed by Spark Plasma Sintering (SPS), also called Pulsed Electric Current Sintering (PECS) [30], using a Dr. Sinter Lab Inc. device (Model 515 S, Kanagawa, Japan, pulsed high DC current, 0-1500 A) at $1300^{\circ} \mathrm{C}$ for 5 min with $75 \mathrm{MPa}$ of constant uniaxial pressure (heating ramp: $100{ }^{\circ} \mathrm{C} / \mathrm{min}$, cooling ramp: $50{ }^{\circ} \mathrm{C} / \mathrm{min}$ ). These parameters have previously been successfully used for the sintering of alumina [31]. During the sintering process, shrinkage and temperature were recorded. Sintered samples were extracted from their graphite die of the SPS device, and thoroughly prepared for micro- and nanomechanical characterization following the RCEP protocol (rectifying, cutting, embedding and polishing) ( $0.5 \mu \mathrm{m}$ diamond slurry), yielding polished surfaces on which micromechanical properties can be measured. In Fig. 2, the samples are shown for the steps described above. 


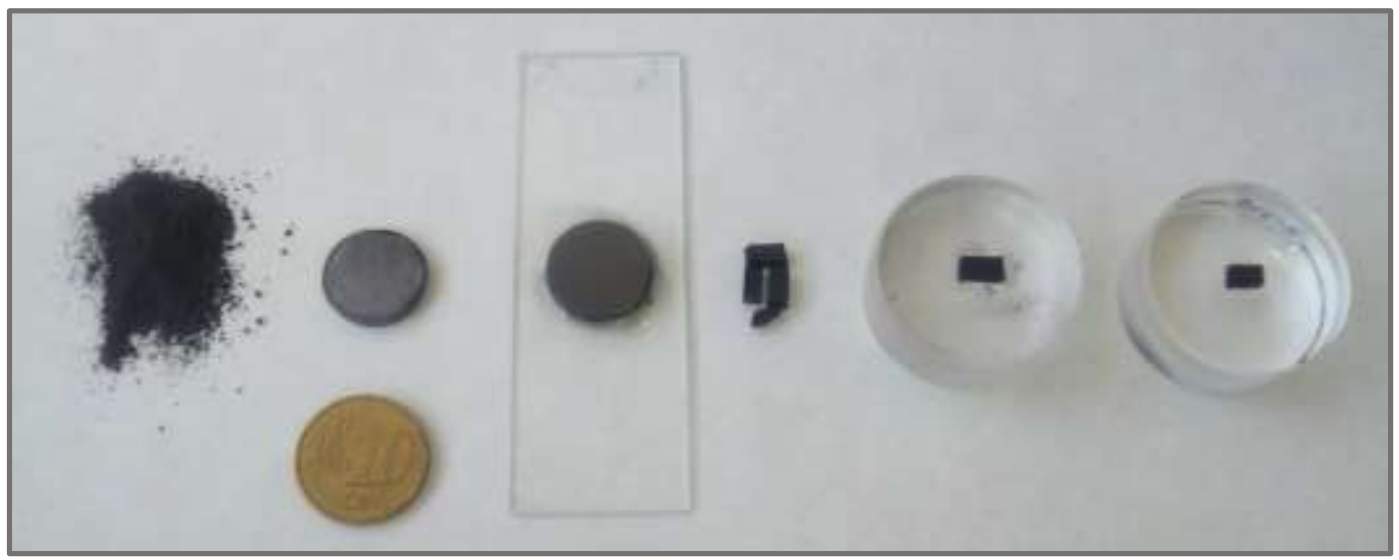

Fig. 2. Samples along the steps of the RCEP preparation protocol. From left to right: CNT-alumina powder after milling and sieving, sintered disc-shaped sample covered with graphite protective wrapping layers for SPS, rectified sample on glass sample holder, rectangular prism sample cuts, embedded sample prism in transparent thermoplastic acrylic mounting material, and polished sample ready to indentation tests. A $0.10 €$ coin has been used for size reference.

\subsection{Mechanical characterization}

In order to assess the presence of toughening effects due to the addition of CNTs, a proper comparison of the mechanical properties in this set of samples was performed by Vickers indentation tests. These tests were performed in a Buehler Wilson ${ }^{8}$ VH1150 Micro Vickers Hardness Tester device with a load of $10 \mathrm{kp}$ $(98 \mathrm{~N})$ and a $5 \mathrm{~s}$ dwell time in series of at least ten indentations for statistics. Fracture toughness, $K_{I c}$, was estimated from the indentation fracture resistance, $K_{I F R}$. These values were obtained by the VIF method with the help of Shetty's model for median cracks, that has been proved as the most accurate equation for alumina polycrystalline ceramics [28]:

$$
K_{I C}=0.023(E / H)^{1 / 2} \mathrm{P} / c^{3 / 2}
$$

in which $E$ and $H$ are the elastic modulus and hardness, respectively. $P$ is the applied load, and $c$ is the length of the crack from the center of the print. More details of the indentation fracture resistance calculation can be seen in [32]. The area of the indentation prints and the length of the cracks were measured by optical microscopy with a x20/0.40 objective and a CCD camera with digital zoom. Good resolution of the optical microscopes was remarked as a major feature for reliably assessing $K_{I F R}$ values by VIF tests [28,33]. Scanning electron microscopy (FEG-SEM, Hitachi S5200) with an acceleration voltage of $5 \mathrm{kV}$, was used to explore the nanostructure of the samples and the cracks due to indentations.

Finally, nanoindentation tests were performed with a Micromaterials Nano Test platform device, using a Berkovich diamond tip. Indentations of depths between 200 and $800 \mathrm{~nm}$ were performed in a series of 25 indentations for statistics, using a load/unload ramp of $2 \mathrm{mN} / \mathrm{s}$. Load-depth curves were analyzed using the Oliver and Pharr method [34], and they were used to determine the relative elastic modulus and nanoindentation hardness. 


\section{Results and discussion}

\subsection{Densities}

The density of the synthesized sample series was measured by Archimedes' method, using 3.985 and 2.1 $\mathrm{g} / \mathrm{cm}^{3}$ as the reference theoretical bulk density for pure alumina [35] and the MWCNT content, respectively. The theoretical densities of the biphasic composites have been estimated, weighting the two densities, according to the wt.\% of each phase, as shown in eq. (2):

$$
\rho_{t h}=\frac{\rho_{1} \rho_{2}}{\rho_{1} \frac{X}{100}+\rho_{2}\left(1-\frac{X}{100}\right)},
$$

where $\rho_{1}$ and $\rho_{2}$ are the theoretical densities of the matrix composite and the secondary phase, respectively, and $X$ is the wt.\% of secondary phase in the composite.

Table 1

Density of samples

\begin{tabular}{llll}
\hline Sample & $\begin{array}{l}\text { MWCNTs } \\
\text { content (wt. \%) }\end{array}$ & $\begin{array}{l}\text { Weighted theoretical } \\
\text { bulk density }\left(\mathrm{g} / \mathrm{cm}^{3}\right)\end{array}$ & $\begin{array}{l}\text { Relative } \\
\text { density }(\%)\end{array}$ \\
\hline BSE-0 & 0 & 3.985 & $85.0 \pm 1.0$ \\
BSE-1 & 1 & 3.950 & $84.2 \pm 2.5$ \\
BSE-2 & 2 & 3.918 & $86.8 \pm 1.1$ \\
BSE-5 & 5 & 3.814 & $85.4 \pm 2.2$ \\
\hline
\end{tabular}

The complete sample series exhibited low relative densities, around $85 \%$ of theoretical density regardless the MWCNTs content (see Table 1), probably due to the use of nanosized $\gamma-\mathrm{Al}_{2} \mathrm{O}_{3}$ as starting powder. This feature is of major relevance regarding the mechanical properties of bulk materials and should be taken into consideration when performing comparisons with other sample series. Though these relative low densities and high porosities may indicate that lower mechanical values should be expected, the influence of the presence of MWCNTs in the mechanical properties can be explored.

\subsection{Vickers hardness}

Samples were indented with a Vickers tip at a $P=98 \mathrm{~N}$ load (HV10). The prints were examined by optical microscopy, and the typical squared prints were revealed. Additionally, the size of the prints and the length of the cracks at the corners were measured in order to evaluate the Vickers hardness and the indentation fracture resistance, respectively. In Fig. 3, the typical print of Vickers indentations can be seen. 


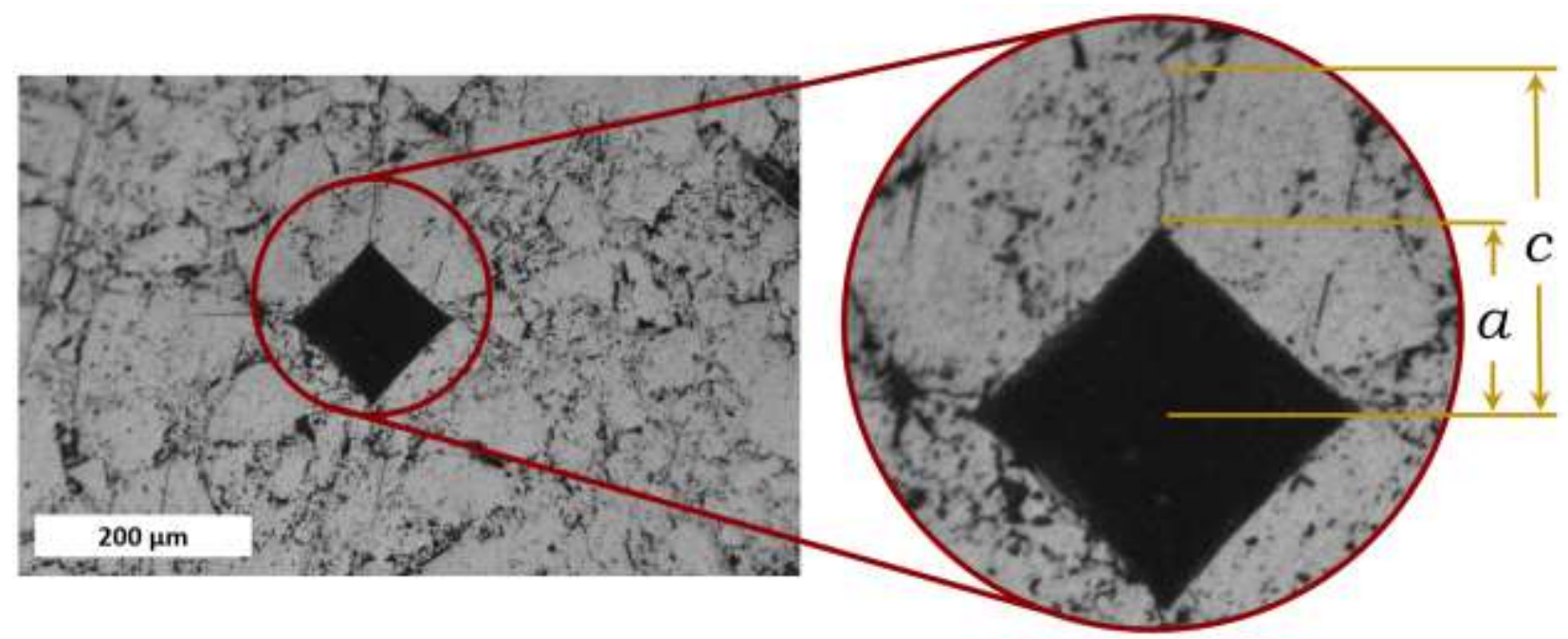

Fig. 3. Left: The optical image of typical squared Vickers indentation print and cracks emerging from print corners. Right: Magnification of indicated area is shown; crack length for $K_{I F R}$ determination (" $c$ ") and print diagonal (" $a$ ") are also indicated.

The values of the hardness are shown in Table 2. As seen, hardness values are low in comparison to typical reported values, as expected. Further, hardness is not significantly affected by the presence of the CNTs. As a reference, a pure sample of full, nearly $100 \%$ dense monolithic polycrystalline alumina exhibits a hardness between 15 and $20 \mathrm{GPa}[4,8,25]$. The decisive factor producing the low values for hardness is the lack of densification, which describes the presence of significant porosities that reduces the volume exposed to mechanical stresses. Some models correlate the porosity and the values of several mechanical properties of the porous, brittle solid ceramics [36-38]. Typically, Young's modulus, bending strength, or the hardness of alumina exhibit a drastic decrease with an increase in porosity [39,40]. Using an empirical exponential model, we are able to estimate the expected hardness of fully dense, pure alumina:

$$
H=H_{0} e^{-b p},
$$

where $H$ is the hardness for a given porosity fraction $p, H_{0}$ is the hardness at porosity zero, and $b$ is a material constant that should be adjusted from the study of different porosities. For the pure alumina sample described in this work, $H=8.1 \mathrm{GPa}$ and $p=15 \%$. Therefore, we can estimate that for a sample of zero porosity, the hardness $H_{0}$ would be between 18.5 and $24.4 \mathrm{GPa}$, using the minimum and maximum reported values of $b$ $=5.5$ [37] and $b=7.35$ [39], respectively. Improvements in densification are, evidently, crucial for hard composites. 
Table 2

Mechanical values of the sample series

\begin{tabular}{llllllll}
\hline Sample & $\begin{array}{l}\text { MWCNTs } \\
\text { content } \\
\text { (wt. \%) }\end{array}$ & $\begin{array}{l}\text { Vickers } \\
\text { Hardness } \\
(\mathrm{GPa})\end{array}$ & c/a & $\begin{array}{l}\text { Indentation } \\
\text { Fracture } \\
\text { Resistance }^{\mathrm{a}} \\
(\text { MGf) }\end{array}$ & $\begin{array}{l}\text { Young's } \\
\text { modulus } \\
\text { (GPa) }\end{array}$ & $\begin{array}{l}\text { Nanoindentation } \\
\text { Hardness } \\
(\mathrm{GPa})\end{array}$ & $\begin{array}{l}\text { Indentation } \\
\text { Fracture } \\
\text { Resistance }^{\mathrm{b}} \\
\text { (MGf) }\end{array}$ \\
\hline BSE-0 & 0 & $8.1 \pm 0.5$ & $2.22 \pm 0.13$ & $7.4 \pm 0.7$ & $121 \pm 12$ & $10 \pm 2$ & $4.1 \pm 0.4$ \\
BSE-1 & 1 & $7.4 \pm 0.6$ & $2.31 \pm 0.15$ & $6.8 \pm 0.7$ & $171 \pm 19$ & $11 \pm 3$ & $4.5 \pm 0.4$ \\
BSE-2 & 2 & $7.9 \pm 0.8$ & $2.35 \pm 0.13$ & $6.8 \pm 0.5$ & $161 \pm 32$ & $9 \pm 4$ & $4.3 \pm 0.3$ \\
BSE-5 & 5 & $7.4 \pm 0.5$ & $2.26 \pm 0.15$ & $7.1 \pm 0.6$ & $260 \pm 97$ & $16 \pm 6$ & $5.7 \pm 0.5$ \\
\hline
\end{tabular}

${ }^{a}$ Calculated with Shetty's equation and pure alumina $E=400 \mathrm{GPa}$ for all samples

${ }^{\mathrm{b}}$ Calculated with Shetty's equation and the corresponding measured $E$ from nanoindentation tests

\subsection{Indentation fracture Resistance}

The measured values of indentation fracture resistance calculated by the VIF method and considering Shetty's formula (1) are listed in Table 2. These values are used to estimate the actual fracture toughness, $K_{I c}$. It is worthy to mention that in a porous material, densification under the indentor occurs, which inevitably leads to less plastic deformation and indentation residual stresses, what could invalidate Shetty's equation. However, we are focused on the comparison of the fracture toughness between this sample series, in order to find its possible correlation with the presence of MWCNTs. As stated above, this indirect fracture toughness measurement method consists of estimating the length of the crack produced at the corner of the Vickers print for a given applied force. In this regard, post-indentation slow crack growth phenomena has been ignored, since the time dependence of the mean crack length after unloading in alumina is negligible $(\sim 1 \%)$ even one month after the indentation tests [33]. Each $K_{I F R}$ value resulted from the average of at least ten indentations. In Shetty's formula (1), the considered values of hardness and crack length are those obtained by Vickers tests. On the contrary, the elastic modulus, $E$, has been taken from sources [35,41]; for fully dense monolithic alumina, $E \approx 400 \mathrm{GPa}$. Given that the actual Young's modulus should be measured for each individual sample in order to perform a rigorous use of the crack model, this is a questionable practice commonly found in many works. Furthermore, the porosity and/or composition may be crucial parameters affecting the value of $E[41]$.

As a general consideration, there is no change on this parameter with the addition of the CNTs. Nevertheless, though densities from this set of samples are below 90\%, the values of fracture toughness are comparable to the values reported in the literature for these CNTs contents, typically ranging from 3 to 7 MGf [7,42]. This set of results invokes contradictory ideas. On one hand, it may suggest that, given the direct dependence of $K_{I c}$ versus density [13], improvements in the fabrication procedures that lead to fully dense samples will involve significantly higher fracture toughness values, as expected. On the other hand, however, these values may be also affected by two artifacts: the presence of significant low hardness $(H)$ values in the denominator, due, principally, to low densities, and the high elastic modulus $(E)$ of pure alumina artificially used in the numerator. 


\subsection{Nanoindentation}

Nanoindentation, in which hardness and elastic modulus are measured simultaneously, is being considered for the mechanical characterization and the measurement of the fracture toughness of the samples $[14,43,44]$. In this work, the mechanical properties of the CMCs were also explored by this technique. During the tests, the indentations penetrated between 200 and $800 \mathrm{~nm}$. Considering the porosity shown in Table 1, it is reasonable to think that the indentations have been performed on a surface with pores similar to the tip size, being relatively easy to indent in a pore or bulk material. Nevertheless, this technique has been validated for a large variety of materials, including ultra-porous materials, such as hybrid silica aerogels [45]. Thus, in order to thoroughly assess the properties of the sample, the tests were performed in a repeated series of 25 indentations for statistics.

During an indentation, the total displacement of the tip is the addition of matrix and indenter deformation, so the relative elastic modulus, $E_{r}$, is given by

$$
\frac{1}{E_{r}}=\frac{1-v_{i}^{2}}{E_{i}}+\frac{1-v^{2}}{E}
$$

where $v_{i}$ and $v$ are the Poisson's ratios, and $E_{i}$ and $E$ are the elastic moduli of the indenter and sample, respectively. The tip is made of diamond, with $v_{i}=0.07$ and $E_{i}=1140 \mathrm{GPa}$, and we are working with alumina samples, which have an estimated Poisson ratio of $v \sim 0.20$ for $15 \%$ porosity $(v \sim 0.24$ for the best case of fully dense alumina) [41]. These values allow us to roughly ignore the term of the indenter in (4), and assume that $1-v^{2} \approx 1$. That is, we can consider $E \approx E_{r}$. For more accurate calculations, for example, only considering that $v_{\mathrm{i}}^{2} \ll 1$ and retaining $v=0.20$, we find that $E \approx 1.48 \cdot \mathrm{E}_{\mathrm{r}}$, for $E_{r}=400 \mathrm{GPa}$, or $E \approx 1.05 \cdot E_{r}$, for $E_{r}=100$ GPa. This is an obvious result: when the elastic modulus of the tested material is a non-negligible fraction of the indenter's elastic modulus, the deviation between $E_{r}$ and $E$ should not be ignored. 


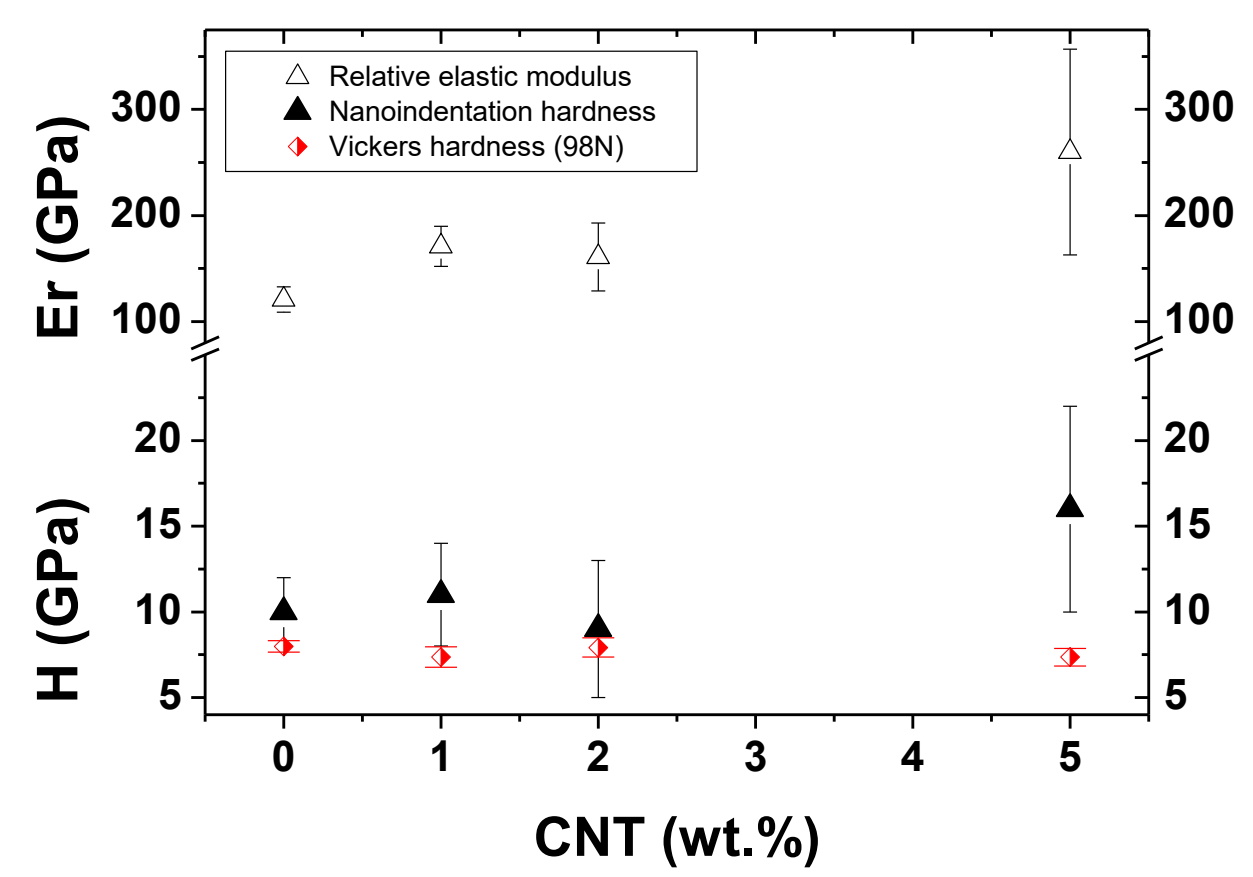

Fig. 4. Relative elastic modulus $\left(E_{\mathrm{r}}\right)$ and Hardness $(H)$ obtained by Berkovich nanoindentations. Vickers Hardness HV10 data from Table 2 is also represented for comparison. Error bars are one standard deviation.

As shown in Table 2 and Fig. 4, the hardness values observed by nanoindentation are higher than those obtained by Vickers tests in all cases. The principal cause of this discrepancy between the values may be due to the applied load, which involves very different indentation depths, known as indentation size effect [46]: the lower the load, the smaller the print, the higher the hardness. This effect is something that must be taken into serious consideration when comparing different studies. On the other hand, the relative elastic modulus presents an increasing trend with the carbon content, as it has been previously reported [14]

\subsection{Indentation Fracture Resistance recalculated}

As explained in the introduction section, the indentation fracture resistance of alumina-based CMCs is classically obtained by the VIF method, considering Young's modulus of the pure alumina from the literature instead of the actual CMC's modulus. Reliable and representative values of $K_{\text {Ic }}$ are desirable to explore the bulk elastic modulus for each composite. Among the many different procedures to obtain Young's modulus, in this study, we have measured this value for each sample by the nanoindentation technique (see Table 2). Thus, despite the possible controversy due to the different length scales at which the different parameters involved in the calculation are measured, namely hardness $(H)$ at the micrometer scale and $E$ at the nanometer scale, it is feasible to calculate the indentation fracture resistance of samples, obtaining the values shown in Table 2 and Fig. 5. 


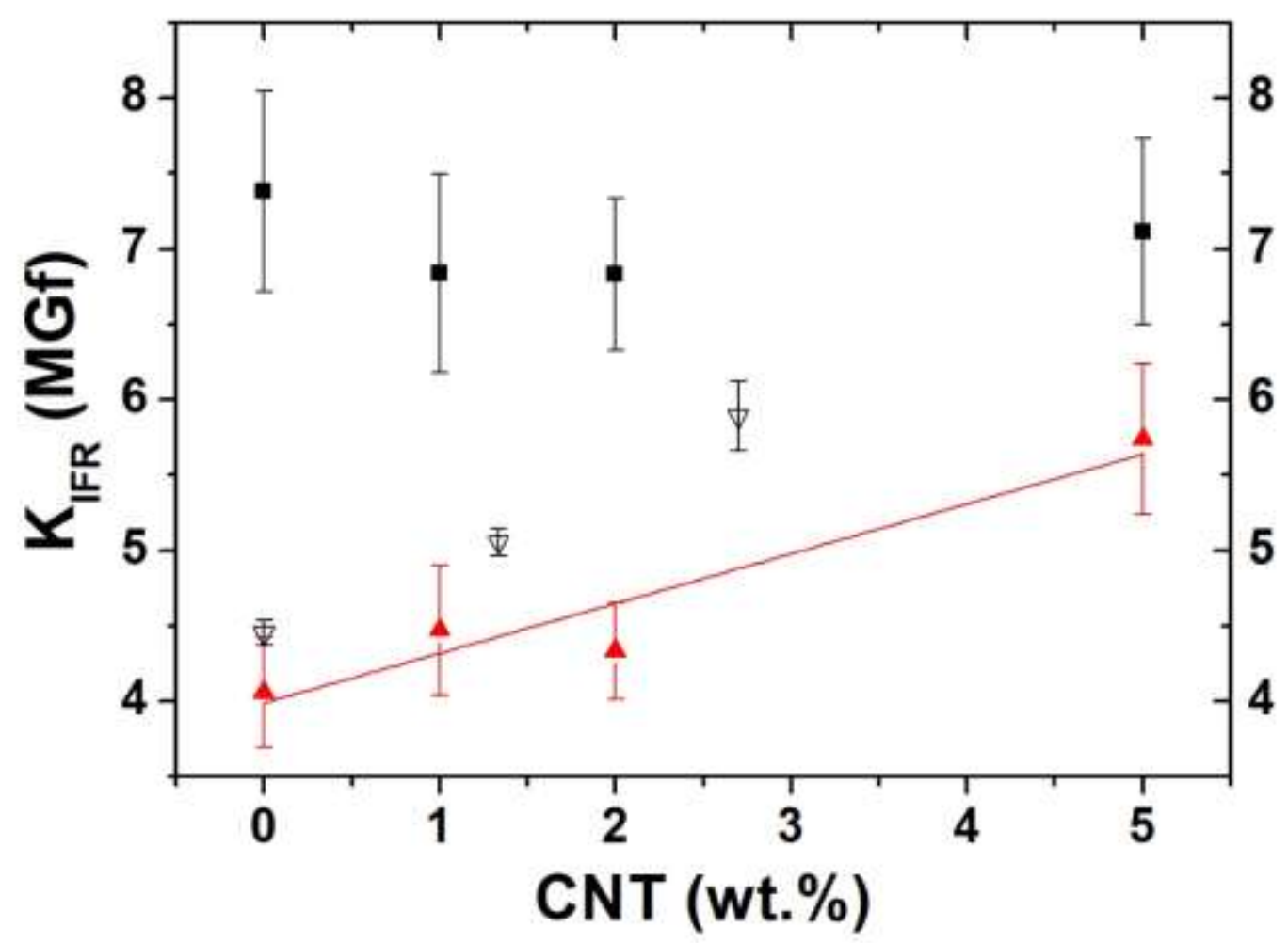

Fig. 5. Indentation fracture resistance values of the alumina-based composites with different MWCNT contents, calculated with Shetty's equation using Young's modulus from bibliography ( $\mathbf{})$ and obtained from nanoindentation tests $(\boldsymbol{\Delta})$. The straight line shown is only a visual guide. Values are averaged from at least 10 indentations. Corrected data from Satam et al [14] is also included $(\nabla)$. Error bars are one standard deviation in all cases.

An increasing behavior of the fracture toughness with the MWCNT concentration has been found using this technique combining a sol-gel route and SPS. Despite the obviously lower values compared to those obtained with a constant $E=400 \mathrm{GPa}$, the pure alumina $K_{I F R}$ result is more realistic and closer to the previously reported values for alumina using several measurement methods [28]. Another study on MWCNT-reinforced alumina, which was obtained by sol-gel method and published by Satam et al. [14], also reported increasing values of indentation fracture resistance calculated with Young's modulus from nanoindentation tests (see Fig. 5). Satam et al. used Anstis' formula for the evaluation of indentation fracture resistance, so we have corrected those values using Shetty's expression for a proper comparison of results. This consistency in improving the indentation fracture resistance with the inclusion of carbon allotropes through the sol-gel procedure supports this technique as a promising route for the exploitation of this reinforcing strategy. 


\subsection{Microstructure exploration}

The analyses of the cracks in the samples by electron microscopy revealed very interesting features. At first sight, the presence of grey dots in the polished surface (see Fig. 6) proves the high porosity mentioned previously, confirmed by the low densities (Table 1). Besides, a good degree of homogenization was observed as the presence of individual CNTs was easily verified, but it should be mentioned that MWCNT bundles were also found, indicating the necessity of improved sample dispersion. Therefore, developing a tool for real time measurement and quantification of the quality of CNT dispersions during sample preparation is of paramount relevance, especially before and after gelation. This will ensure perfect dispersion and the absence of coils and bundles that will eventually act as defects at the macroscopic scale, affecting densification or fracture toughness.
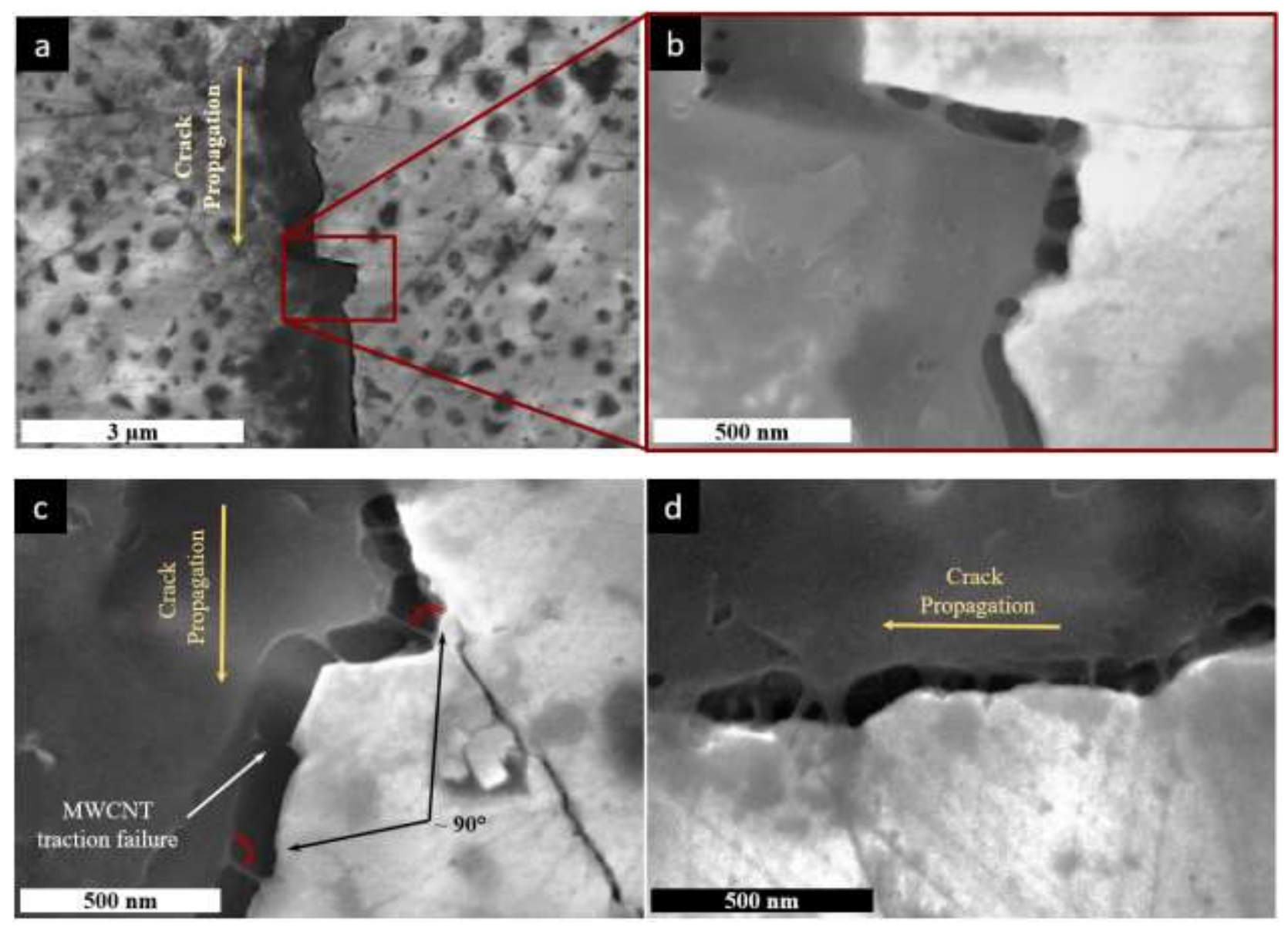

Fig. 6. SEM micrographs of different cracks produced during Vickers indentations. a shows evident porosity of samples. In b, c, and $\mathbf{d}$ pulled-out MWCNTs bridging both sides of the running crack are observed, revealing crack-bridging as a mechanism hindering crack propagation. In $\mathbf{c}$ and $\mathbf{d}$, partial reorientation of MWCNTs perpendicular to the crack sides can be seen and is highlighted by the curved, red double lines. In c, tensile-stressed MWCNT failure is shown by the white arrow.

However, the most startling feature is how intragranular CNTs were clearly seen in fracture surfaces emerging from the bulk samples (Fig. 6). One goal of this kind of strategy for reinforcing composites fabrication is the transfer of tensile loads from the ceramic matrix to the MWCNTs. The toughening mechanisms that may appear, especially in intragranular CMCs, are mainly crack-bridging and crack- 
deflection [13]. These mechanisms can be found easily in our samples by looking along the cracks produced during the Vickers test, as shown in Fig. 6. MWCNTs are acting as reinforcement bridges, "sewing" both sides of the cracks, forcing the deflection of crack propagation (Fig. 6a and 6b), and eventually, failing (Fig. $6 c$ ), where a significant amount of the crack propagation energy would be released. This is the mentioned crack-bridging effect, and it would be eventually present in the composite response to the fracture propagation independently of the fracture mode. The presence of these toughening phenomena explain the increase of the recalculated indentation fracture resistance (section 3.4) of the samples with nanotubes. Another remarkable fact is that all CNTs found in the cracks seem to be almost perpendicular to the crack propagation direction due to the reorientation of exposed segments of MWCNTs, as indicated in the micrographs in Fig. 6 and sketched in Fig. 7.
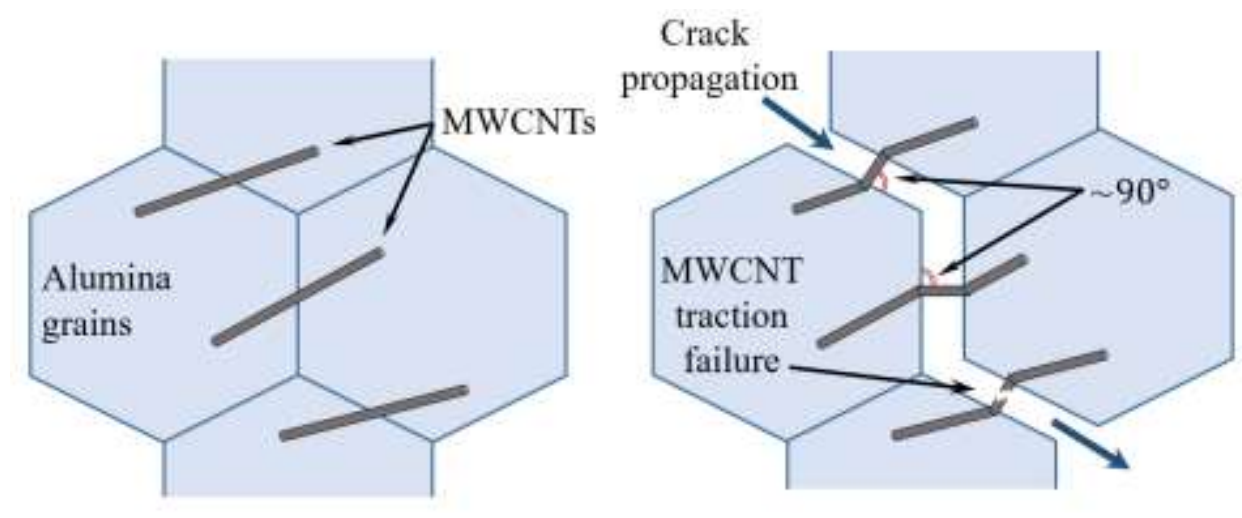

Fig. 7. This sketch highlights partial reorientation and traction failure of CNTs along crack propagation between grains. Only intergranular fracture mode has been sketched, but the same idea is also proposed for intragranular cracks.

\section{Conclusions}

Sample preparation needs urgent revision to improve the density and to adequately incorporate the MWCNTs within the ceramic matrix in order to obtain the highest mechanical values. The measurement of every parameter present on an indentation fracture resistance equation is also vital for a realistic comparison, even with samples of the same series. Though typical values of the indentation fracture resistance calculated with the classical Young's modulus of pure alumina from the literature are higher for all samples, the recalculated indentation fracture resistance reveals an increasing behavior when considering the actual elastic moduli of samples, obtained in this case by nanoindentation. Microstructural inspection by SEM reveals the presence of new toughening phenomena such as crack bridging and crack deflection. These mechanisms transfer tensile loads from alumina matrix to the reinforcement nanophase during the propagation of the cracks, which explain the increasing behavior of recalculated $K_{I F R}$ with MWCNT content. 


\section{Acknowledgements}

Project PGC2018-094952-B-100 financed by FEDER / Ministerio de Ciencia e Innovación - Agencia Estatal de Investigación and project P12-FQM-1079 from Junta de Andalucía and funding support to FQM393 from Junta de Andalucía are acknowledged. V. M-F. thanks the grant from V Plan Propio de Investigación de la Universidad de Sevilla. P. R-A acknowledge European Social Fund, Empleo Juvenil European Plan and project PGC2018-094952-B-I00 from FEDER / Ministerio de Ciencia e Innovación Agencia Estatal de Investigación. The help from the technical staff from the CITIUS is acknowledged. The authors would like to thank the work by the National Institutes of Health, USA for the development of the ImageJ https://imagej.nih.gov/ij/ software. Comercial Química Massó is also acknowledged for supplying the boehmite precursor $\mathrm{Nyacol}^{\circledR}$.

\section{Compliance with ethical standards}

Conflict of interest The authors declare that they have no conflict of interest

\section{References}

[1] J.N. Coleman, U. Khan, W.J. Blau, Y.K. Gun'ko, Small but strong: A review of the mechanical properties of carbon nanotube-polymer composites, Carbon N. Y. 44 (2006) 1624-1652. https://doi.org/10.1016/j.carbon.2006.02.038.

[2] E. Zapata-Solvas, D. Gómez-García, A. Domínguez-Rodríguez, On the microstructure of single wall carbon nanotubes reinforced ceramic matrix composites, J. Mater. Sci. 45 (2010) 2258-2263. https://doi.org/10.1007/s10853-009-4126-z.

[3] I. Ahmad, B. Yazdani, Y. Zhu, Recent advances on carbon nanotubes and graphene reinforced ceramics nanocomposites, Nanomaterials. 5 (2014) 90-114. https://doi.org/10.3390/nano5010090.

[4] I. Ahmad, H. Cao, H. Chen, H. Zhao, A. Kennedy, Y.Q. Zhu, Carbon nanotube toughened aluminium oxide nanocomposite, J. Eur. Ceram. Soc. 30 (2010) 865-873. https://doi.org/10.1016/j.jeurceramsoc.2009.09.032.

[5] K.S. Lee, B.K. Jang, Y. Sakka, Damage and wear resistance of Al2O3-CNT nanocomposites 
fabricated by spark plasma sintering, J. Ceram. Soc. Japan. 121 (2013) 867-872. https://doi.org/10.2109/jcersj2.121.867.

[6] G. Yamamoto, M. Omori, K. Yokomizo, T. Hashida, K. Adachi, Structural characterization and frictional properties of carbon nanotube/alumina composites prepared by precursor method, Mater. Sci. Eng. B Solid-State Mater. Adv. Technol. 148 (2008) 265-269. https://doi.org/10.1016/j.mseb.2007.09.013.

[7] K. Lee, C.B. Mo, S.B. Park, S.H. Hong, Mechanical and Electrical Properties of Multiwalled CNTAlumina Nanocomposites Prepared by a Sequential Two-Step Processing of Ultrasonic Spray Pyrolysis and Spark Plasma Sintering, J. Am. Ceram. Soc. 94 (2011) 3774-3779. https://doi.org/10.1111/j.1551-2916.2011.04689.x.

[8] M.H. Bocanegra-Bernal, C. Dominguez-Rios, J. Echeberria, A. Reyes-Rojas, A. Garcia-Reyes, A. Aguilar-Elguezabal, Spark plasma sintering of multi-, single/double- and single-walled carbon nanotube-reinforced alumina composites: Is it justifiable the effort to reinforce them?, Ceram. Int. 42 (2016) 2054-2062. https://doi.org/10.1016/j.ceramint.2015.09.060.

[9] C.B. Mo, S.I. Cha, K.T. Kim, K.H. Lee, S.H. Hong, Fabrication of carbon nanotube reinforced alumina matrix nanocomposite by sol-gel process, Mater. Sci. Eng. A. 395 (2005) 124-128. https://doi.org/10.1016/j.msea.2004.12.031.

[10] G. Yamamoto, T. Hashi, Carbon Nanotube Reinforced Alumina Composite Materials, in: Compos. Their Prop., InTech, 2012. https://doi.org/10.5772/48667.

[11] F.J. Torres-Canas, C. Blanc, C. Zamora-Ledezma, P. Silva, E. Anglaret, Dispersion and individualization of SWNT in surfactant-free suspensions and composites of hydrosoluble polymers, J. Phys. Chem. C. 119 (2015) 703-709. https://doi.org/10.1021/jp5092015.

[12] Q. Chen, C. Saltiel, S. Manickavasagam, L.S. Schadler, R.W. Siegel, H. Yang, Aggregation behavior of single-walled carbon nanotubes in dilute aqueous suspension, J. Colloid Interface Sci. 280 (2004) 91-97. https://doi.org/10.1016/j.jcis.2004.07.028.

[13] G.D. Zhan, J.D. Kuntz, J. Wan, A.K. Mukherjee, Single-wall carbon nanotubes as attractive toughening agents in alumina-based nanocomposites, Nat. Mater. 2 (2003) 38-42. https://doi.org/10.1038/nmat793.

[14] M.K. Satam, L. Gurnani, S. Vishwanathe, A. Mukhopadhyay, Development of Carbon Nanotube Reinforced Bulk Polycrystalline Ceramics with Intragranular Carbon Nanotube Reinforcement, J. Am. Ceram. Soc. 99 (2016) 2905-2908. https://doi.org/10.1111/jace.14425. 
[15] L. Esquivias, P. Rivero-Antúnez, C. Zamora-Ledezma, A. Domínguez-Rodríguez, V. MoralesFlórez, Intragranular carbon nanotubes in alumina-based composites for reinforced ceramics, J. SolGel Sci. Technol. 90 (2019) 162-171. https://doi.org/10.1007/s10971-018-4834-4.

[16] J. Sun, L. Gao, M. Iwasa, T. Nakayama, K. Niihara, Failure investigation of carbon nanotube/3YTZP nanocomposites, Ceram. Int. 31 (2005) 1131-1134. https://doi.org/10.1016/j.ceramint.2004.11.010.

[17] T.A. Saleh, V.K. Gupta, Characterization of the Chemical Bonding between Al2O3 and Nanotube in MWCNT/ A12O3 Nanocomposite, Curr. Nanosci. 8 (2012) 739-743. https://doi.org/10.2174/157341312802884418.

[18] J. Yi, W. Xue, T. Wang, Z. Xie, Mechanical and electrical properties of chemically modified MWCNTs/3 Y-TZP composites, Ceram. Int. 41 (2015) 9157-9162. https://doi.org/10.1016/j.ceramint.2015.03.008.

[19] G. Bepete, E. Anglaret, L. Ortolani, V. Morandi, K. Huang, A. Pénicaud, C. Drummond, Surfactantfree single-layer graphene in water, Nat. Chem. 9 (2017) 347-352. https://doi.org/10.1038/nchem.2669.

[20] B.E. Yoldas, A Transparent Porous Alumina, Ceram. Bull. 54 (1975) 289-290. https://ci.nii.ac.jp/naid/10030764894/ (accessed June 20, 2018).

[21] C. Barrera-Solano, L. Esquivias, G.L. Messing, Effect of Preparation Conditions on Phase Formation, Densification, and Microstructure Evolution in La- $\beta-\mathrm{Al} 2 \mathrm{O} 3 / \mathrm{Al} 2 \mathrm{O} 3$ Composites, J. Am. Ceram. Soc. 82 (1999) 1318-1324. https://doi.org/10.1111/j.1151-2916.1999.tb01914.x.

[22] M. Piñero, M.M. Mesa-Díaz, D. de los Santos, M. V. Reyes-Peces, J.A. Díaz-Fraile, N. de la RosaFox, L. Esquivias, V. Morales-Florez, Reinforced silica-carbon nanotube monolithic aerogels synthesised by rapid controlled gelation, J. Sol-Gel Sci. Technol. 86 (2018) 391-399. https://doi.org/10.1007/s10971-018-4645-7.

[23] S.R. Inbaraj, R.M. Francis, N.V. Jaya, A. Kumar, Processing and properties of sol gel derived alumina-carbon nano tube composites, Ceram. Int. 38 (2012) 4065-4074. https://doi.org/10.1016/j.ceramint.2012.01.064.

[24] G.-D. Zhan, A.K. Mukherjee, Carbon Nanotube Reinforced Alumina-Based Ceramics with Novel Mechanical, Electrical, and Thermal Properties, Int. J. Appl. Ceram. Technol. 1 (2005) 161-171. https://doi.org/10.1111/j.1744-7402.2004.tb00166.x.

[25] M. Michálek, K. Bodišová, M. Michálková, J. Sedláček, D. Galusek, Alumina/MWCNTs 
composites by aqueous slip casting and pressureless sintering, Ceram. Int. 39 (2013) 6543-6550. https://doi.org/10.1016/j.ceramint.2013.01.087.

[26] J. Sun, L. Gao, X. Jin, Reinforcement of alumina matrix with multi-walled carbon nanotubes, Ceram. Int. 31 (2005) 893-896. https://doi.org/10.1016/j.ceramint.2004.10.002.

[27] H. Miyazaki, Y.I. Yoshizawa, Correlation of the indentation fracture resistance measured using high-resolution optics and the fracture toughness obtained by the single edge-notched beam (SEPB) method for typical structural ceramics with various microstructures, Ceram. Int. 42 (2016) 78737876. https://doi.org/10.1016/j.ceramint.2016.01.116.

[28] H. Miyazaki, Y. Yoshizawa, A reinvestigation of the validity of the indentation fracture (IF) method as applied to ceramics, J. Eur. Ceram. Soc. 37 (2017) 4437-4441. https://doi.org/10.1016/j.jeurceramsoc.2017.07.027.

[29] P. Souza Santos, H. Souza Santos, S.P. Toledo, Standard transition aluminas. Electron microscopy studies, Mater. Res. 3 (2000) 104-114. https://doi.org/10.1590/s1516-14392000000400003.

[30] K.Q. Dang, M. Kawahara, S. Takei, M. Nanko, Effects of pulsed current waveforms on sample temperature and sintering behavior in PECS of alumina, J. Japan Soc. Powder Powder Metall. 56 (2009) 780-787. https://doi.org/10.2497/jjspm.56.780.

[31] R. Cano-Crespo, B. Malmal Moshtaghioun, D. Gómez-García, A. Domínguez-Rodríguez, R. Moreno, High-temperature creep of carbon nanofiber-reinforced and graphene oxide-reinforced alumina composites sintered by spark plasma sintering, Ceram. Int. 43 (2017) 7136-7141. https://doi.org/10.1016/j.ceramint.2017.02.146.

[32] D.K. Shetty, A.R. Rosenfield, W. Duckworth, Analysis of Indentation Crack as a Wedge-Loaded Half-Penny Crack, J. Am. Ceram. Soc. 68 (1985) C-65-C-67. https://doi.org/10.1111/j.11512916.1985.tb15288.x.

[33] H. Miyazaki, Y.I. Yoshizawa, Refined measurements of indentation fracture resistance of alumina using powerful optical microscopy, Ceram. Int. 40 (2014) 2777-2783. https://doi.org/10.1016/j.ceramint.2013.10.039.

[34] W.C. Oliver, G.M. Pharr, An improved technique for determining hardness and elastic modulus using load and displacement sensing indentation experiments, J. Mater. Res. 7 (1992) 1564-1583. https://doi.org/10.1557/JMR.1992.1564.

[35] F. Cardarelli, Materials Handbook, 2nd ed., Springer London, London, 2008. https://doi.org/10.1007/978-1-84628-669-8. 
[36] V.R. Salvini, V.C. Pandolfelli, D. Spinelli, Mechanical Properties of Porous Ceramics, in: Recent Adv. Porous Ceram., IntechOpen, 2018: pp. 171-199. https://doi.org/http://dx.doi.org/10.5772/57353.

[37] R.W. Rice, Comparison of physical property-porosity behaviour with minimum solid area models, J. Mater. Sci. 31 (1996) 1509-1528. https://doi.org/10.1007/BF00357860.

[38] K.K. Phani, S.K. Niyogi, Young's modulus of porous brittle solids, J. Mater. Sci. 22 (1987) $257-$ 263. https://doi.org/10.1007/BF01160581.

[39] N. Miyazaki, T. Hoshide, Influence of Porosity and Pore Distributions on Strength Properties of Porous Alumina, J. Mater. Eng. Perform. 27 (2018) 4345-4354. https://doi.org/10.1007/s11665018-3500-x.

[40] R.M. Spriggs, Expression for Effect of Porosity on Elastic Modulus of Polycrystalline Refractory Materials, Particularly Aluminum Oxide, J. Am. Ceram. Soc. 44 (1961) 628-629. https://doi.org/10.1111/j.1151-2916.1961.tb11671.x.

[41] M. Asmani, C. Kermel, A. Leriche, M. Ourak, Influence of porosity on Young's modulus and poisson's ratio in alumina ceramics, J. Eur. Ceram. Soc. 21 (2001) 1081-1086. https://doi.org/10.1016/S0955-2219(00)00314-9.

[42] M.H. Bocanegra-Bernal, J. Echeberria, J. Ollo, A. Garcia-Reyes, C. Domínguez-Rios, A. ReyesRojas, A. Aguilar-Elguezabal, A comparison of the effects of multi-wall and single-wall carbon nanotube additions on the properties of zirconia toughened alumina composites, Carbon N. Y. 49 (2011) 1599-1607. https://doi.org/10.1016/j.carbon.2010.12.042.

[43] L. Melk, J.J. Roa Rovira, F. García-Marro, M.L. Antti, B. Milsom, M.J. Reece, M. Anglada, Nanoindentation and fracture toughness of nanostructured zirconia/multi-walled carbon nanotube composites, Ceram. Int. 41 (2015) 2453-2461. https://doi.org/10.1016/j.ceramint.2014.10.060.

[44] M. Sebastiani, K.E. Johanns, E.G. Herbert, G.M. Pharr, Measurement of fracture toughness by nanoindentation methods: Recent advances and future challenges, Curr. Opin. Solid State Mater. Sci. 19 (2015) 324-333. https://doi.org/10.1016/j.cossms.2015.04.003.

[45] N. de la Rosa-Fox, V. Morales-Flórez, J.A. Toledo-Fernández, M. Piñero, R. Mendoza-Serna, L. Esquivias, Nanoindentation on hybrid organic/inorganic silica aerogels, J. Eur. Ceram. Soc. 27 (2007) 3311-3316. https://doi.org/10.1016/j.jeurceramsoc.2007.02.209.

[46] S.J. Bull, T.F. Page, E.H. Yoffe, An explanation of the indentation size effect in ceramics, Philos. Mag. Lett. 59 (1989) 281-288. https://doi.org/10.1080/09500838908206356. 
